\title{
The GI Simulated Clinic in the Era of COVID-19: a Comparison of Virtual to In-Person Delivery
}

\author{
C. K. Ferris ${ }^{1}$ (D) D. M. Williams ${ }^{1} \cdot$ E. Shen ${ }^{1} \cdot$ J. M. Jackson ${ }^{1} \cdot$ J. T. Bruggen ${ }^{1}$ \\ Accepted: 5 November 2021 / Published online: 19 November 2021 \\ (c) The Author(s) under exclusive licence to International Association of Medical Science Educators 2021
}

\begin{abstract}
The COVID-19 pandemic has significantly impacted medical education; thus, there is a need to better understand the effectiveness of virtual learning compared to in-person learning. This is a single-center, cross-sectional study of first-year medical students who attended a gastroenterology simulated clinic activity in person in 2018 and 2019 or virtually in 2020. Participants were surveyed on the activity's relevance and effectiveness. Students' assessment of the virtual clinic's effectiveness and relevance was not significantly different from the in-person version of the activity. In addition, most students rated the virtual clinic as effective for learning about telemedicine.
\end{abstract}

Keywords Virtual learning · Simulated activity · Telemedicine · COVID-19

\section{Background}

The COVID-19 pandemic has significantly impacted medical education [1-5]. Both pre-clinical and clinical medical student training have been affected, as social distancing measures have altered in-person learning activities including direct patient care experiences. Technologies such as asynchronous online modalities and virtual meetings have been incorporated into medical education in order to provide remote education to learners outside of the traditional classroom or clinical setting [2].

While lecture-based curricula have been readily transitioned from in-person to virtual-learning modalities, there remains a need to effectively integrate clinical reasoning into the newly adapted curricula. The COVID-19 pandemic has thus accelerated the need for innovative virtual learning tools and curricula [4]. In this study, we integrated virtual learning, simulation, and telemedicine into the Gastroenterology Applied Clinical Skills (GEACS) clinic—an engaging learning activity for pre-clinical medical students-and compared students' perception of its effectiveness when delivered virtually to prior learners' assessment of in-person delivery. We hypothesize that students' perception of overall

$\triangle$ C. K. Ferris

chloekferris@wustl.edu

1 Department of Internal Medicine, Wake Forest School of Medicine, 475 Vine St, Winston-Salem, NC 27101, USA effectiveness would not be statistically different between the virtual GEACS clinic delivered in April 2020 and the previous in-person GEACS clinics in 2018 and 2019.

\section{Activity}

This was a single-center, cross-sectional study of firstyear medical students at Wake Forest School of Medicine (WFSM) who attended the GEACS clinic in April 2020. All students were required to participate in this learning event, as part of the first-year gastroenterology (GI) course. The activity's learning objectives for students were to recognize the clinical features of the diseases presented, practice differential diagnosis formation and diagnostic study selection for the cases presented, and practice history-taking skills learned in the clinical skills course.

The virtual GEACS clinic activity was conducted via online videoconference software (WebEx Version 40.4.0; Cisco) and was designed to closely mimic the in-person event previously described by Williams et al. [7]. The same four cases-appendicitis, acute cholecystitis, ulcerative colitis, and pancreatic cancer-were utilized in the previous in-person and virtual GEACS clinic iterations. While standardized patients (SPs) participated in the in-person GEACS clinics in previous years, third- and fourth-year medical students were recruited by the GI course director to role-play the patient cases remotely in the 2020 iteration. At the time 
of this study, these students had been removed from direct patient care duties and restricted to distance learning due to the COVID pandemic, as recommended by the Association of American Medical Colleges [6]. One student who served as a patient actor during this activity is a co-author $(\mathrm{CF})$ and was excluded from data analysis. A brief one-hour training session was conducted to instruct the student actors on how to present their cases.

Logistics of the virtual GEACS clinic closely mimicked those of the original learning event, which has been previously published [7]. Students were assigned to small groups of three to four students and instructed to take turns serving as the interviewer for each of the four patient encounters. Students were instructed to utilize the videoconferencing software to begin the virtual patient encounter with the student actor. The student interviewer was given 15 min to perform the history and an assessment of the patient's general appearance (for the previous in-person iterations, students had $20 \mathrm{~min}$ to perform a history and physical exam for each encounter). Following each encounter, students had $10 \mathrm{~min}$ to discuss the case, as in the previous in-person iterations. During the case discussion, students were asked to submit their prioritized differential diagnosis and to suggest up to four lab tests and/or one diagnostic imaging test for each patient. After the activity concluded, the first-year medical students reviewed the cases during a debrief session with the GI course director. No summative assessment of students' performance was conducted, as this learning activity was purely formative.

All student learners and student actors were invited via email request to participate in a voluntary, post-event learner evaluation survey, accessed electronically using Redcap software (Version 9.5; Vanderbilt University). The survey asked respondents to assess the learning activity's overall effectiveness, relevance to their future career, and effectiveness in meeting each of its stated learning objectives. Respondents' identities were masked and therefore remained unknown to the GI course director and study investigators. Reminder emails were sent to students in the weeks to months following the initial request to optimize survey response rates. Survey data results were stratified by year in medical school and analyzed with descriptive statistics using SPSS software (Version 26; IBM). Comparison between the in-person iterations in 2018 and 2019 and the April 2020 telehealth iteration of the GEAC clinic with regard to respondents' assessment of the overall effectiveness of the learning activity was performed using independent sample T-tests.

This study was reviewed and approved by the WFSM Institutional Review Board (IRB00066226).

\section{Results}

One hundred and forty-six first-year medical students participated in the virtual GEACS clinic in 2020 as learners, and 36 third- and fourth-year medical students participated as student actors. Forty (27\%) of the first-year medical students and 18 of (50\%) third- and fourth-year medical students who participated in the virtual GEACS clinic responded to the post-activity survey.

Third- and fourth-year student actors' and first-year student learners' responses to the learner evaluation survey are summarized in Tables 1 and 2, respectively. There was no statistically significant difference between student perception of overall effectiveness for virtual versus in-person delivery, $t(93)=1.16, p=0.251$. Most students in both the learner and actor groups assessed the virtual GEACS clinic to be both effective and relevant. Regarding instructional design, 97.5\% of student learner respondents agreed the small-group format was appropriate, $95.0 \%$ agreed the activity's pace and duration was appropriate, and $100 \%$ agreed that the problemsolving aspect of the activity was intellectually stimulating. Eighty-five percent of student learners preferred classes that

Table 1 Student actor rating of effectiveness and relevance of the virtual GEACS clinic activity, 2020 (respondent $n=18$ )

\begin{tabular}{|c|c|}
\hline Survey item & Mean (standard deviation) \\
\hline $\begin{array}{l}\text { Overall effectiveness of the GI simulated clinic activity for you as a simulated patient? }(1=\text { poor; } \\
10=\text { excellent }) \text { ? }\end{array}$ & $8.65(1.00)$ \\
\hline $\begin{array}{l}\text { Your perception of the overall effectiveness of the GI simulated clinic activity for the students you worked } \\
\text { with }(1=\text { poor; } 10=\text { excellent }) \text { ? }\end{array}$ & $8.78(1.06)$ \\
\hline How relevant was the content of this learning activity to your role as a future physician? & $\begin{array}{l}\text { Extremely (\%) or Quite Relevant (\%) } \\
83.3 \%\end{array}$ \\
\hline $\begin{array}{l}\text { Effectiveness of the encounter for learning about the clinical features of the diseases presented in this } \\
\text { learning activity? }\end{array}$ & $\begin{array}{l}\text { Extremely (\%) or Quite Effective (\%) } \\
88.9 \%\end{array}$ \\
\hline $\begin{array}{l}\text { Effectiveness of the SP encounters/role play for practicing your diagnostic reasoning skills related to the } \\
\text { diseases presented in this learning activity? }\end{array}$ & $77.8 \%$ \\
\hline $\begin{array}{l}\text { Effectiveness of the SP interviews/role play for reinforcing history-taking skills you have learned in the } \\
\text { Clinical Skills } 1 \text { course? }\end{array}$ & $77.8 \%$ \\
\hline
\end{tabular}


Table 2 Student learner rating of effectiveness and relevance of the GEACS clinic activity, in-person ${ }^{7}$ vs. virtual delivery

\begin{tabular}{lll}
\hline Survey item & $\begin{array}{l}\text { In-person GEACS clinic learners, } \\
2018 \text { and 2019 }(n=80)\end{array}$ & $\begin{array}{l}\text { Virtual GEACS clinic } \\
\text { learners, 2020 }(n=40)\end{array}$ \\
\hline $\begin{array}{l}\text { Overall effectiveness of the GI simulated clinic activity (1= poor; } \\
10=\text { excellent)? }\end{array}$ & $\begin{array}{l}\text { Mean (standard deviation) } \\
9.20(1.01) \\
\text { Extremely (\%) or Quite Relevant (\%) } \\
9.95(1.09)\end{array}$ \\
$\begin{array}{l}\text { How relevant was the content of this learning activity to your role as a future } \\
\text { physician? }\end{array}$ & $\begin{array}{l}\text { Extremely (\%) or Quite Effective (\%) } \\
\text { Effectiveness of the encounter for learning about the clinical features of the }\end{array}$ & $88.8 \%$ \\
diseases presented in this learning activity? & $96.3 \%$ & $90.0 \%$ \\
Effectiveness of the SP encounters/role play for practicing your diagnostic & \\
reasoning skills related to the diseases presented in this learning activity? & & $87.5 \%$ \\
Effectiveness of the SP interviews/role play for reinforcing history-taking skills & $91.3 \%$ & \\
you have learned in the Clinical Skills 1 course? & & $87.5 \%$ \\
\hline
\end{tabular}

include this activity's type of small-group problem-solving activity versus those that do not.

When asked to evaluate the effectiveness of the virtual GEACS clinic for learning about telemedicine delivery, most $(82.5 \%)$ students rated the activity as extremely or quite effective. When asked about the effectiveness of videoconferencing as a modality for the learning content presented, $82.5 \%$ students rated it as "extremely" or "quite effective."

Additionally, the surveys asked students to provide narrative comments regarding activity's relevance, effectiveness, and areas for improvement. Table 3 includes a summary of themes and representative quotations from students' responses.

\section{Discussion}

In this study, students' assessment of the virtual GEACS clinic's overall effectiveness was not statistically different from the in-person implementation of this activity, thus confirming our hypothesis. Medical students found the virtual clinic to be an effective method for learning about telemedicine, which has become increasingly important in the context of the current global pandemic and for the future of healthcare delivery.

What made the virtual GEACS clinic directly comparable to the in-person activity were the patient cases [7], which were readily translatable to the telehealth version. However, we did note some differences between virtual and in-person delivery in terms of students' assessment of the learning activity. Compared to the in-person student group, a lower percentage of learners in the virtual implementation group assessed the activity as effective for learning about clinical features of the diseases represented and for practicing diagnostic reasoning skills. This is not surprising, however, given students in the virtual group were unable to directly perform physical examinations on these patients, which could have yielded additional clinical features that would shape their differential diagnoses for each case.

Table 3 Representative quotations from medical students on the virtual GEACS clinic activity

\begin{tabular}{|c|c|}
\hline General Theme & Direct Quotations from Student Surveys \\
\hline Learner engagement & $\begin{array}{l}\text { "This makes the content come to life. It can be hard to remember why we are putting ourselves } \\
\text { through hours of studying and this reminds us why." -MS1 } 1^{\text {a }}\end{array}$ \\
\hline Telemedicine education & $\begin{array}{l}\text { "The GEACS clinic was a really great introduction to telemedicine. It was done really well and } \\
\text { sufficiently took the place of in person SP interactions during the pandemic." -MS1 }\end{array}$ \\
\hline Integration of knowledge into clinical setting & $\begin{array}{l}\text { "Case-based learning of the GEACS clinic was very helpful in integrating material we had } \\
\text { learned in lecture with clinical presentation. The group size was good in that everyone was } \\
\text { participating and could easily work together/collaborate on each case." -MS1 }\end{array}$ \\
\hline Deliberate practice in skill acquisition & $\begin{array}{l}\text { "This learning activity provided practice with all of those and allowed integration of the GI } \\
\text { material. Every block should have something like this." -MS1 }\end{array}$ \\
\hline Logistical/training issue & "Sometimes there was confusion on which patient we were seeing." -MS1 \\
\hline Learning through reflection & $\begin{array}{l}\text { "This was a great experience for me in thinking through the patient experience with a particular } \\
\text { illness. It helped me solidify learning of the material in a different way." -MS } 3^{\text {b }}\end{array}$ \\
\hline
\end{tabular}

${ }^{a}$ MS1, first-year student learner

${ }^{\mathrm{b}} \mathrm{MS} 3$, third-year student actor 
The virtual GEACS clinic provided opportunities for both first-year medical students and more advanced third- and fourth-year medical students to learn about the GI cases they were solving or performing, respectively. Compared to student learners in the in-person delivery group, a similar percentage of student actor respondents assessed the virtual delivery as effective for learning about the clinical features of the diseases represented; this is likely due to one of the latent learning aspects of this activity, which is reinforcement of prior learning required of the student actors in order to properly portray the patient cases to which they were assigned. Rønning's and Bjørkly's review examining the use of clinical role playing in mental health education suggested that role-playing enhances students' therapeutic and communicative skills and enhances students' involvement, self-efficacy, and empathy in mental health practice [8]. Likewise, our study suggests role-playing patients may provide educational benefits to medical students. However, the benefits differed in scope for these versus the first-year students: a lower percentage of student actors assessed the activity as effective for practicing diagnostic reasoning skills or history-taking skills versus learners in both the virtual and in-person delivery groups, likely because these patient provider tasks were not performed by student actors.

The virtual GEACS clinic allowed first-year medical students to be introduced to telemedicine in an integrative and interactive way. This instructional delivery method not only exposes medical students to this modality of healthcare delivery by giving them direct practice of the skills required, but it can also help them understand the challenges and barriers involved. Perhaps, early exposure to telemedicine will inspire the next generation of students to address these challenges with innovative solutions.

Limitations of this study included a small sample size and a single institution study design. Additionally, our study examined student perceptions and attitudes through surveys, lacking higher-level learning outcomes such as directly observed students' communication skills or diagnostic reasoning performance.

The virtual format of the GEACS clinic could easily be applied to other types of simulated patient encounters. Future studies of simulated virtual patient encounters could include assessment of knowledge, clinical reasoning skills, or other clinical skills performance for both student interviewers and student actors in order to better understand the potential benefits of this modality.

Data Availability All data generated or analyzed during this study are included in this published article.

\section{Declarations}

Competing Interests The authors declare no competing interests.

\section{References}

1. Ahmed H, Allaf M, Elghazaly H. COVID-19 and medical education. Lancet Infect Dis. 2020;20(7):777-8. https://doi.org/10. 1016/S1473-3099(20)30226-7.

2. Dedeilia A, Sotiropoulos MG, Hanrahan JG, Janga D, Dedeilias P, Sideris M. Medical and surgical education challenges and innovations in the COVID-19 era: a systematic review. In Vivo (Brooklyn). 2020;34(3 suppl):1603-11. https://doi.org/10.21873/invivo.11950.

3. Sandhu P, de Wolf M. The impact of COVID-19 on the undergraduate medical curriculum. Med. Educ. [Online] 2020;25(1):1 764740. https://doi.org/10.1080/10872981.2020.1764740.

4. Almarzooq ZI, Lopes M, Kochar A. Virtual learning during the COVID-19 pandemic: a disruptive technology in graduate medical education. J Am Coll Cardiol. 2020;75(20):2635-8. https://doi. org/10.1016/j.jacc.2020.04.015.

5. Tolsgaard MG, Cleland J, Wilkinson T, Ellaway RH. How we make choices and sacrifices in medical education during the COVID-19 pandemic. Med Teach. 2020;42(7):741-3. https://doi. org/10.1080/0142159X.2020.1767769.

6. Prescott J. Important guidance for medical students on clinical rotations during the coronavirus (COVID-19) outbreak. 2020. Available: https://www.aamc.org/news-insights/press-releases/ important-guidance-medical-students-clinical-rotations-duringcoronavirus-covid-19-outbreak.

7. Williams DM, Bruggen JT, Manthey DE, Korczyk SS, Jackson JM. The GI simulated clinic: a clinical reasoning exercise supporting medical students' basic and clinical science integration. MedEdPORTAL. 2020;16(1):10926. https://doi.org/10.15766/ mep_2374-8265.10926.

8. Rønning SB, Bjørkly S. The use of clinical role-play and reflection in learning therapeutic communication skills in mental health education: an integrative review. Adv Med Educ Pract. 2019;10:41525. https://doi.org/10.2147/AMEP.S202115.

Publisher's Note Springer Nature remains neutral with regard to jurisdictional claims in published maps and institutional affiliations. 